\title{
Adverbs in Saudi Northern Region Dialect of Arabic (SNRDA)
}

\author{
Khalaf M. J. AlShammiry ${ }^{1 \& 2}$ \\ ${ }^{1}$ King Saud University, College of Languages and Translation (COLT), Riyadh, KSA \\ ${ }^{2}$ Northern Border University (NBU), Northern Border Region, Arar, KSA \\ Correspondence: Khalaf M. J. AlShammiry, Vice Presidency for Development, Quality and Community Service, \\ Northern Border University Main Campus, Administration Building, Arar, P. O. Box 1321. E-mail: \\ reemsaqir99@yahoo.com
}

Received: November 27, 2015 Accepted: December 23, 2015 Online Published: January 31, 2016

doi:10.5539/ijel.v6n1p128 URL: http://dx.doi.org/10.5539/ijel.v6n1p128

\begin{abstract}
With my belief that there is not a comprehensive theory of adverb position, Iatridou (1990), Bobaljik \& Jonas (1996), in this paper, I investigate the morph-syntax and distribution of adverbs in one of the Saudi dialects, Saudi Northern Region Dialect of Arabic (SNRDA); a dialect that is spoken in the Northern Region of Saudi Arabia. I will show that adverbs at least in SNRDA are not descriptively as simple as it is assumed for other dialects of Arabic studied by Nuha (2005) and in the Modern Standard Arabic (MSA) investigated by Fassi $(1997,1998)$. What is interesting in this dialect is that intonation plays role in where the adverbs appear and how they are interpreted; in addition, with the change of the adverb position, there is a change in the meaning. The contribution of this paper is that it discusses adverbs in a dialect which many of its syntactic facts remain largely un-described and adds to our understanding of the syntactic behavior of the adverbs.
\end{abstract}

Key words: Adverbs morpho-syntax and distribution, intonation, preverbal and postverbal adverbs

\section{Introduction}

Although the analysis of adverbs in the syntactic and semantic levels receives relatively much attention in languages like English, French, German and Italian; see Jackendoff (1972), Travis (1988), Pollock (1989, 1997), Emonds (1976), Belletti (1990, 1994), Cinque (1994, 1999 and 2004) and Ernst (1984, 1998 and 2002), adverbs in Modern Standard Arabic (MSA) and dialects of Arabic have scarcely been investigated or studied, Fassi (1993, 1997, 1998 and 2013), AlAqad (2013) and Nuha (2005). This paper aims at discussing the morph-syntax and distribution of adverbs in one of the Saudi dialects, Saudi Northern Region Dialect of Arabic (henceforth SNRDA); a dialect that is spoken in the northern region of Saudi Arabia. I will show that adverbs at least in SNRDA are not descriptively as simple as it is assumed in other dialects of Arabic Studied by Nuha (2005) and the Modern Standard Arabic (MSA) investigated by Fassi $(1997,1998)$ and that intonation plays role in where and how the adverbs are interpreted; in addition, it will be shown that with the change of the adverb position, there is a change in the meaning. The contribution of this paper is that it discusses adverbs in a dialect which many of its syntactic facts remain largely un-described and adds to our understanding of the syntactic behavior of the adverbs.

The organization of the paper is as follows: in section 2, I review some of the findings of studies done on adverbs in other languages showing that, to this day, there is not any comprehensive theory that could account for adverbs in all languages. Section 3 pinpoints some of the findings of the studies done on adverbs in some dialects of Arabic and MSA. In section 4, I present and discuss the morpho-syntax and distribution of adverbs in Saudi Northern Region Dialect of Arabic (SNRDA). Section 5 concludes by outlining descriptive and theoretical conclusions and remaining puzzles.

\section{Studies Done on Adverbs of Other Languages}

Since Jackendoff's (1972) statement "the adverb is perhaps the least studied and most maligned part of speech", a number of analyses for adverbs have been put forth in both syntactic and semantic fields. To account for the fact that adverbs appear in various positions in the clause, Keyser (1968) and Baltin (1982) assume that adverbs themselves move; they come up with what is referred to as "Transportability Convention". To them, adverbs first appear to the right of the clause; then, they move to any positions to the left periphery of Verb Phrase, Inflectional Phrase or Complementizer Phrase. Pollock $(1989,1997)$ on the other hand, investigating English and 
French, assumes that the verb or the auxiliary movement results in adverbs surfacing in preverbal or postverbal positions. However, Belletti $(1990,1994)$ accounts for the appearance of the adverb behind the subject in French by proposing that the subject is in a topic position.

In (1999), in the line with Kayne's (1994) anti symmetric structure "adjunction" and Rizzi's (1997) Structure of the Complementizer Phrase, the (CP) layer, of the left periphery of the clause, Cinque studying French, English, Hebrew, and Chinese as well as other languages proposes that adverbs are base generated specifiers that occur in a fixed universal hierarchal order with a single underlying position and there are 30 to 40 levels of functional head specifier positions. In case when the adverb appears in two different positions having different meaning, Cinque argues for a movement derivation. Heads of those phrases are semantically motivated in which the relative order of heads is represented by asymmetric c-commanding of those heads. Movement of the verb/auxiliary or the subject is considered to be the reason behind the different surface positions of the adverbs.

A number of works have refuted and shown that Cinque's approach falls short; Contra Cinque, Costa (2000 and 2004) shows the possibility of coordinating adverbs of different semantic classes in Italian.

\section{O Paulo le Frequentemente e simpaticamente o livroaavo}

Joan often and nicely reads the book to the grandmother.

Ernst (2002), contra Cinque, also shows that although speaker and subject oriented adverbs have rigid order, quantificational and aspectual have variable ordering with meaning difference and participant PPs has free ordering with no meaning difference; (See also works done on Turkish language by Stephen \& Ayse (2001), and on Indian language by Archna (2006) for the same argument).

In addtioin, Ernst (1984) shows that several adverbs can appear in one sentence in one position. If we accept Cinque's approach, that there is only one single position for each adverb, we would need a highly articulated clause structure that could accommodate the piled up adverbs:

2. He apparerently never merely skims papers but rather reads each on carefully.

The same phenomenon is attested in a V2-language like German; Haider (2000) shows that one of the challenges of Cinque's approach is stacking of adverbials in an adverbial cluster.

3. (In zweiTagen am Strand wenn die Sonneuntergeht) wirstdu essehen (Haider, 2000)

In two days at the beach when the sun set will you it see

\section{Abendswegen des Staus hat erdiesen Platzgemieden}

In the evening because of the traffic congestion has he this place avoided.

In (3), locative, time, and conditional adverbials form a cluster preceding the fronted finite verb; in (4), time and reason adverbials form a cluster.

Moreover, Potsman (1997), contra Cinque, shows that adverbs are not rigidly ordered in a sentence.

\section{John will (probably wisely/wisely probably) accept your help (Potsman, 1997)}

The rebels have (now perhabs/perhabs now) surrendered.

On the other hand, Ernest $(1998,2002)$, observing that the hierarchy is too rigid to account for the data concerning scope, proposes that there is a semantic requirement for adverb positioning and adverbs are freely adjoined. She argues that the semantic feature on the head determines the ability of that head to license an adverb. So she argues that English and French languages have different distinct features on their Ts which result in contrast between the two languages (Haider, 2000, 2004 for the same approach).

Again, Ernst's (2002) is not without problems. As it states by Cinque (2004), if we take Cinque's (1999) main evidence for his fixed hierarchy proposal for adverbs, Ernst does not provide any semantic explanation why cross linguistically the number and type of adverbs and their order match the number and type and relative order of functional head morphemes.

Moreover, there is no complete understanding of the semantic of each adverb; Ernst proposal gives no answers to questions like: why for instance speaker and subject oriented adverbs have rigid order while quantificational and aspectual have variable ordering with meaning difference; whereas, participant PPs has free ordering with no meaning difference; and why certain verbs can precede only certain adverbs in a language like French; why not all adverbs. And in a system with TP and VP layers, why adverbs adjoined to TP depend on the form of that verb, participial or finite.

Ernst's (2002) analysis of adverbs does not provide any explanation for the variation in the following: 
6. Honestly John has spoken about the truth to his mother.

7. John has spoken about the truth to his mother honestly.

Why the adverb honestly surfacing clause initially in (6) cannot be interpreted as a manner adverb like when it appears clause finally in (7).

We could see that none of the Cinque's (1999) and Ernst (2002)is not without problems; not to mention, both analyses do not consider that there are other adverbials that are to be investigated and account for before theories are put forth; for instance, adverbials that modify adjectives like the adverbial heel "very/extremely" in SNRDA. Thus, I would say that much more work needs to be done in order to reach a comprehensive theory that could account for adverbs in all languages. Next, works done on Arabic adverbs are discussed.

\section{Adverbs in Arabic}

Very few works have been done on Arabic adverbs and all are descriptive which shows the complexity of the adverbs and the unavailability of a comprehensive theory. Nuha (2005), discussing two dialects of Arabic, Palestinian Arabic (PA) and Hijazi Arabic (HA), following Jackendoff's (1972), assumes that there are two main types of adverbs: verb phrase adverbs and sentence adverbs; in both types, adverbs are optionally positioned in the sentence with no fixed order:

\section{VP $\rightarrow \quad($ ADV) V (NP) ADV) (Nuha, 2005) \\ 9. $\mathrm{S} \rightarrow$ (S-ADV) S' (S-ADV)}

As (8 and 9) show, Nuha assumes that adverbs can be either left-adjoined or right-adjoined to the verb; whereas, sentence adverbs occur alternately in initial or final position. Nuha gives the he following examples:

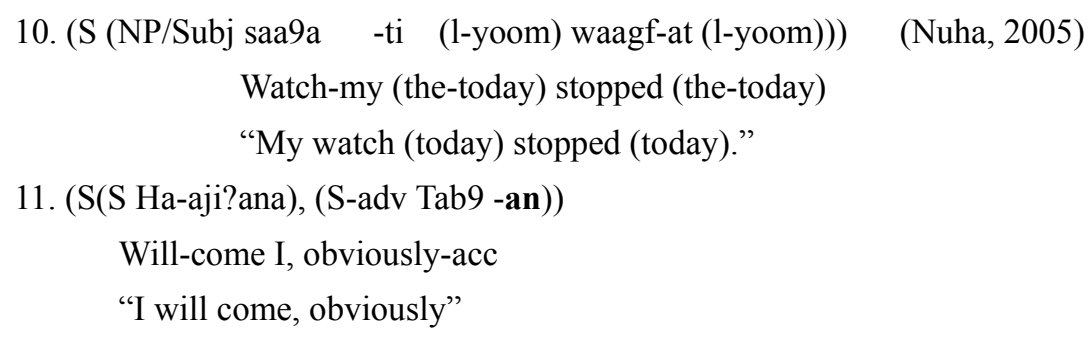

According to Nuha (2005), the temporal adverb of time l-yoom "today" in (10) can appear "around the verb" either between the subject $s a a 9 a-t i$ "my watch" and the main verb taagf-at "stopped" or after the main verb. The same could be said for the sentence adverb Tab9-an "obviously" in (11) which can alternate in the linear order of the sentence; it can appear initially or finally.

Al-Aqad (2013), comparing English and Arabic adverbs positions using X-bar theory, shows that there are more than one position for adverbs in Modern Standard Arabic (MSA) sentence and that with the change in adverb position there is a change in the sentence meaning.

Fassi (1997, 1998), as in Cinque (1996), studying adverbs in MSA, assumes that adverbs are event modifiers "adjuncts" generated in specifier positions of functional projections lower than the verb. They move from there to high positions in the clause structure and adjoined to specs of Aspect, Tense, Modality, etc.

According to him, there are three adverb classes; class 1 adverbs are those adverbs that cannot move as high as the Inflectional Phrase (IP) or the left periphery of the clause. They can only be positioned higher than the object or the prepositional phrase (PP) complement. Class 2 adverbs are those adverbs that can move higher than the participle IP or a modal phrase (ModP). Finally, class 3 adverbs are those adverbs that can precede Negation Phrase (NegP) and occur sentence initially in the complementizer phrase, (CP) layer "sententional adverbs". To cite some of the Fassi's examples,

Class 1 adverbs:

12. ?a'rifujayyid-an 1-jawaab-a (Fassi, 1997)

I-know perfect-acc the-answer-acc

"I know the answer perfectly"

13. Kanna r-rajul-u (*jayyid-an) ya'rifu 1-jawaab-a

Was the-man-nom perfect-acc knows the-answer-acc

"The man had knowledge (*perfectly) of the answer." 
14. *jayyid-anya'rifu r-rajul-u l-jawaab-a

perfect-acc knows the-man-nom the-answer-acc

Compared to (12 and 13), we could see in (14) that the sentence is ungrammatical if the adverb jayyid-an "perfect-acc" appears preverbally. I will shortly show that a sentence like (14) above is grammaticalin the SNRDA clause.

Class 2 adverbs:

15. lamyakun r-rajuluqabluqad?akala t-tuffaah-a (Fassi, 1997)

not is the-man.nom before indeed ate the-apples-acc

"The man had not really eaten apples before."

In (15), the adverb qablu "before" precedes the model particle qad "indeed" which precedes the tensed IP.

Class 3 adverbs:

16. tab'anlam ya?kul r-rajul-u t-tuffaah-a (Fassi, 1997)

evidently, not eats the-man. nom the-apples-acc

"Evidently, the man did not eat apples."

In (16), the adverb tab'an "evidently" appears at the left periphery of the clause.

According to Fassi, there is a hierarchal fixed order for those three types of adverbs in MSA.

17. tab'anlam yakum r-rajul-u ?abad-an y-a?lulukathirr-an (Fassi, 1997)

evidently, not is the-man.nomat all-acc eats a lot-acc

"Evidently, the man was not at all eating a lot."

As (17) shows, class 3 adverbs come first at the left periphery of the clause; then, class 2 adverbs come lower in a position to the left of the main verb; and class 1 adverbs come lower in the clause structure. That is to say, speaker oriented adverbs precede subject oriented ones which precede manner adverbs.

Fassi states that, it is not as English adverbs, Jackendoff (1972), adverbs in Arabic show meaning change depending on the position in which they occur. A bare noun phrase (NP) adverb in Arabic has either a lexically driven subject orient or a manner oriented interpretation. In other words, an adverb cannot be ambiguous between manner and subject oriented interpretation.

After I have gone over the previous works that have been done on MSA and some dialects of Arabic, in the next section, I will discuss the morpho-syntax and distribution of adverbs in SNRDA.

\section{Morpho-syntax and Distribution of Adverbs in SNRDA}

\subsection{Morpho-syntax of Adverbs in SNRDA}

In this subsection, I discuss the morpho-syntax of adverbs in SNRDA. As in English, adverbs in SNRDA usually tell you when, where, how, in what manner, or to what extent an action is performed. They come in the form of Adjective phrase (AP), Noun Phrase (NP) or $b$-prefixed nouns (Note 1).

20. Ali wiSalsaalim(-an) AP

Ali arrived intact

"Ali arrived healthy."

21. Ali wiSalmashi(-an) NP

Ali arrived walking

"Ali arrived walking."

22. Ali wiSalb-sir?ahb-prefixed noun

Ali arrived with speed "quickly"

"Ali arrived quickly."

We see in (20) the adjective phrase (AP) saleem-an "healthy" is used as an adverb of manner; and in (21), the noun phrase (NP) mashi-an "walking" is used; in both (20 and 21), we could see the presence of the clitic-an; a clitic that is used for emphasis, emphasizing how the action is done. In (22), the $b$-prefixed noun, $b$-sir? $a h$ "quickly" is used. 
In SNRDA, as the examples above show, adverbs can be expressed by using mere adjectives, saalim "healthy"; other adverbs can be expressed by using mere nouns that are derived from verbs as in mashi "waking" which is derived from the verb misha "walk"; below are some examples of adverbs derived from verbs:

Table 1. Examples of adverbs derived from verbs

\begin{tabular}{llll}
\hline The verb & The meaing & The adverb derived & The meaing \\
\hline dharab & "hit/beat" & dharb & "strongly/severely" \\
shirib & "drink" & shirb & "fully" \\
ribat & "tighen" & rabt & "tightly" \\
bika & "cray" & bka & "too much crying" \\
\hline
\end{tabular}

Moreover, many adverbs are morphologically derived by attaching the prefex $b$-to nouns; as in $b$-sir?ah "quickly" in (22) above, where the prefix $b$ - is attached to the nounsir?ah "speed". Here are some more examples of $b$-noun adverbs:

Table 2. Examples of adverbs derived by attaching the prefix $b$ - to the noun

\begin{tabular}{llll}
\hline The noun & The meaing & The adverb derived & The meaing \\
\hline quwwa & "strength" & b-quwwa & "strongly" \\
?adil & "justice" & b-?adil & "justly" \\
Sidq & "honesty" & b-Sidq & "honestly" \\
?aSabiyya & "nervousness" & b-?aSabiyya & "nervously" \\
\hline
\end{tabular}

Now, although many adverbs start with the prefix $b$-and those expressed through mere nouns or adjectives to express how an action is performed, they are many other ones that do not go with these paradigms; to cite some, we have for example duub "just/right now", ba?d "yet", daayim "always",kwayyis "well", lillah "never", ihtimaal "probably", ma ? umr "never", faqaT, bass "just, only", qhaad, hnaak "there", hnayyah "here", shway "little", shwayshway "little little", wara "back", alatuul "immediately" andmishwain, minsaa? "before some time". That is to say, adverbs do not seem to have any specific characteristics that distinguish them apart; Emonds (1985) assumes specific characteristics for English and French adverbs; - ly and -ment respectively.

SNRDA has other syntactic structures that function as adverbials, PP and subordinate clauses. Here is an example where an adverbial PP is used.

23. aliwiSalb-sayyarah (adverbial of manner)

Ali arrived by car

"Ali arrived by a car."

In (23), the preposition phrase b-sayyarah "by a car" is an adverbial that modifies the manner of arrival. One might wonder how this adverbial differs from one that is discussed earlier under adverbs as in the adverb $b$-sir? ah "quickly" (the example repeated here for convenience).

24. aliwiSalb-sir?ah

Ali arrived quickly

"Ali arrived quickly."

b-sir?ah "quickly" in (24) compared to b-sayyarah "by a car" in (23), as the meaning and the English gloss show, is considered as an adverb of one word rather than an adverbial of two words; and it is most of the time shorted to $b$-saa? "quickly".

Subordinate clauses can also function as adverbials. See the following:

25. aliwiSalqabilyaaSalfahad (subordinate clause as an adverbial)

Ali arrived before arrived Fahad

"Ali had arrived before Fahad arrived."

In (25), the subordinate clause qabilyaa Salfahad "before Fahad arrived" functions as and adverbial that modifies the verb of the matrix clause wiSal "arrived". 
To complete the picture of adverbs, it is worth mentioning that there are sentential adverbs that modify the entire clause such as baTTab?/Tab?an "of course", aSSiheeh "truly", al-wikaad "truly", ?aSlan "basically, emooman "generally", awwalan "firstly", akheeran "finally", bsarahah/sarahah "frankly", haqeeqah "truely" and lisuu? alhadh "unfortunately". See the following sentence.

26. wikaad, aliwiSal (sentential adverb)

truth, Ali arrived

"Truly, Ali arrived."

We see in (26), that the adverb wikaad "truly" occurs sentence initially. Notice the use of the pause right after the adverb; it represents a short silence when the sentence is uttered.

Before investigating the syntactic distribution of adverbs in SNRDA, it is worth mentioning that SNRDA has what is referred to as degree adverbs, those adverbs that modify adjectives and other adverbs like heel/balheel, marrah, jidan, and ktheer which all means "very/extremely":

27. alithaki heel (degree adverb)

Ali smart very

"Ali is very smart."

In (27), the adverbial heel "very" is modifying the adjective thaki "smart".

In addition, to add emphasis to an adjective or adverb to a great degree or extremity, speakers of this dialect reduplicate the word with intonation difference; they place higher pitch on the second word.

28. Ali thikiTHIKI

Ali smartSMART

"Ali is very smart."

29. Ali tiweel TIWEEL

Ali tall TALL

"Ali is very tall."

In both (28 and 29), the noun thiki "smart" and the adjective tiweel "tall" are reduplicated with higher pitch on the second word. After going over the morphology of the adverbs and adverbials in SNRDA, next, I discuss the distribution of those adverbs in the SNRDA sentence.

\subsection{Distribution of Adverbs in SNRDA}

\subsubsection{The Clause Structure of the SNRDA}

Before discussing the distribution of adverbs in SNRDA, it is important to know that SNRDA has three main word orders SVO, VSO, and VOS. Those word orders are associated with different intonations.

30. alisharasayyarah SVO

ali bought a car

"Ali bought a car."

"As for Ali, he bought a car."

"ALI bought a car."

"Did Ali buy a car?"

31. sharaalisayyarah VSO

bought Ali a car

"Ali bought a car."

"Did Ali buy a car?"

32. sharasayyarahali

bought a car Ali

"As for Ali, he BOUGHT A CAR." (informative)

(Ali is topicalized)

(Ali is foused)

(yes/no question)

\author{
(informative) \\ (yes/no question)
}

As we could see from (30), in a SVO order, the sentence can be interpreted differently depending on the 
intonation used. If the words in the sentence are uttered with the same intonation; it is an informative sentence. However, if the subject of the sentence Ali receives higher pitch, it could be interpreted as a focus or a topic; we could see the use of a pause right after the subject. Not only that, even without the use of a wh-item, the sentence is interpreted as a yes/no question or a question tag. In VSO word order in (31), the sentence is either informative or a yes/no question; despite the fact the VSO word order is attested and grammatical, it is rarely used by native speaker of this dialect. In (32), the subject Ali appears final in the clause. It is interpreted as a topic whereas the VP, the verb and the object, are focused. In all word orders, the subject fully agrees with the verb in person, number and gender.

The internal structure of the clause structure in SNRDA is more complex than it seems to be.

33. alima rah ykuunyal?abkuurah

Ali not will be playing football

"Ali will not be playing football."

In (33), we could see that, in the SNRDA clause structure, the negation item $m a$ "not" is to the left of the future marker rah "will"; lower than both of these two elements, there is the verb yakuun "be" which is followed by the main verb of the sentence $y a l$ ? ab "playing"; all are followed by the object kuurah "football"; (A full discussion of the clause structure is something beyond the scope of this paper; the reader is referred to Khalaf's dissertation (2007)).In the rest of the paper, it is suffice to discuss the distribution of adverbs in this dialect using SVO sentences. After showing the structure of the clause in SNRDA, next, I discuss the distribution of adverbs in the dialect.

\subsubsection{Adverbs Distribution in SNRDA}

With neutral interpretation, adverbs are classified into two main groups: preverbal adverbs like, ihtimaal "probably", ihyaanan "often", ma ?umr "never" and $m a$ ? ad "no longer" which always appear preverbally and postverbal adverbs like, b-biTa "slowly", bsaa? "quickly" and b-quwwa "strongly" which always appear clause final. Besides, the SNRDA clause has what is always referred to as sentential adverbials like wikaad "truly" and saraahah "frankly". All these types are addressed in the following subsections.

\subsubsection{Preverbal Adverbs}

This subsection discusses mainly the preverbal adverbs. Those preverbal adverbs are divided into two types; the first type is those adverbs that always appear in a position to the left of the subject in a neutral sentence likeihtimaal "probably" and ihyaanan "often"; I will label them as "left periphery adverbs" just to distinguish them from other types of adverbs. The second type of preverbal adverbs isma-adverbs like ma ?umr "never" and $m a$ ? ad "no longer". Both types of adverbs are discussed next.

\subsection{Left Periphery Adverbs}

In a neutral sentence, adverbs like ihtimal "probably" and ihyaanan "often" always appear in a position to the left of the subject. Let us see the following examples.

34. ihyaananaliyizuurfahad

Often Ali visit Fahad

"Ali often visits Fahad."

35. *ali(ahyaanan)yiruur(ahyaanan)fahad(ahyaanan)

Ali oftenvisit oftenFahadoften

"Ali often visitsFahad."

In the neutral sentence (34), we could see that the adverb ahyaanan "often" occupies a position to left of the subject. (35) shows that any other position renders the sentence ungrammatical. Moreover, in the same position to the left of the subject, the preverbal adverb ihyaanan "often" can be pronounced with a higher pitch; in this case, it is interpreted as a topic and with much higher pitch when it is interpreted as a focus. We could see the use of a comma indicating a pause right after the adverb.

36. ahyaanan, aliyizuurfahad

Often, Ali visit Fahad

"As for often, Ali visits Fahad

"OFTEN, Ali will visits Fahad." 
*“Ali often visits Fahad."

As (36) shows, the adverb ahyaanan "often" is only interpreted as either a topic or a focus but never takes a neutral interpretation.

When the subject Ali precedes the neutral, or topicalized or even focused adverb ahyaanan "often", the subject is always interpreted as a topic or a focus.

37. ali,ahyaananyizuurfahad

Ali oftenvisit Fahad

"As for Ali, he often visits Fahad."

"As for Ali, as for often, he visits Fahad."

"As for Ali, OFTEN, he visits Fahad."

"ALI, he often visits Fahad."

"ALI, as for often, he visits Fahad."

*"Ali often visits Fahad"

In (37), we could see that the subject Ali precedes the adverb ahyaanan "often"; whether the adverb is neutral or topicalized or even focused, the subject is always interpreted as either a topic or a focus; neutral interpretation of the subject renders the sentence ungrammatical. Before closing this section, it is worth mentioning that the adverb ahyaanan "often" can appear clause final; it can appear clause final if and only if either the verb phrase including the subject Ali yizuurfahad "Ali visits Fahad." is focused or the verb phrase yizuurfahad "visits Fahad" is focused while the subject $A l i$ is topicalized. This is clear from the way the sentence is pronounced; speakers use higher pitch on those elements that are topicalized or focused and pause right before the adverb is uttered; not to mention, they pause right after the topicalized subject.

38. aliyizuurfahad, ahyaanan.

Ali visitFahad often

"ALI VISITS FAHAD, often"

*"Ali often visits Fahad."

39. ali, yizuurfahad, ahyaanan

Ali visitFahad often

"As for Ali, he often VISITS FAHAD."

*"Ali often visits Fahad."

In (38), the verb phrase along with the subject aliyizuurfahad "Ali visits Fahad" is focused. In (39), the subject ali is topicalized while the verb and the object yizuurfahad "visits Fahad" are focused. Any other interpretation is not accepted. What is important is that the adverb ahyaanan "often" is interpreted as neutral at the end of the sentence.

In this subsection, I have shown that the left periphery preverbal adverbs like ahyaanan "often" always precede the subject in a neutral sentence; these adverbs can be topicalized or focused at the left periphery of the clause. It is only when the verb phrase along with the subject is focused or the subject is topicalized and the verb and its object are focused, these adverbs surface clause final. Next, the preverbal $m a$-adverbs are discussed.

\subsubsection{2 ma-adverbs}

This subsection concerns the distribution of $m a$-adverbs like ma 9umr "never" and ma 9ad "no longer". These adverbs are internally complex as they are formed out of a negation element $m a$ and a noun 9umr; separately, the noun is used to mean "age, life, or spirit".

40. ?umralitiweel

age Ali long

"Ali's age is long."

41. Allitsawee-ihyqassir al-?umr

That do-it shorten the-age

"What you do shortens the age." 
An interesting fact about the $m a$-adverbs is that no element can come in between the $m a$ and the noun which shows that adjacency requirement must be respected.

42. *ma aliumr-*(ih) zaarFahad

Not Ali age-himvisited Fahad

"Ali never visited Fahad."

(42) shows that an element like the subject Ali cannot appear in a position in between the ma and 9umr. Being homophonous with the sentential negation $m a$ someone might conclude that $m a$ used with these adverbs is just the $m a$ used with sentential negation. That is not really true; both mas can appear in the same clause. To avoid confusion, from now on, I will be glossing $m a-$ ? umr as "never".

43. maumralima zaarFahad

neverAli not visited Fahad

"Ali has not never visited Fahad."

(Ali always visited Fahad.)

In (43), we could see that the sentential negation $m a$ cooccurs with the $m a$ in the $m a$-adverb ma 9umr "never" in the same clause.

These adverbs always appear in a position to the left of the subject with only and only neutral interpretation.

44. maumralizaarfahad

never Ali visited Fahad

"Ali never visited Fahad."

*"As for never, Ali visited Fahad."

*"NEVER, Ali visited Fahad."

45. * alizaar (ma umr (Note 2)) fahad (ma umr)

Ali visited never Fahad never

"Ali never visited Fahad."

(44) shows that the ma-adverb ma 9umr "never" is always interpreted as neural. (45) shows that this adverb never occupiesa postverbal position. As in the left periphery adverbs discussed above, when the subject precedes the $m a$-adverb, it is always interpreted as a topic or a focus. In this case, there is an obligatorily presence of a resumptiveclitic attached to the $m a$-adverb which fully agrees with the subject.

46. ali, ma ?umr-ihzaarfahad

Ali never-him visited Fahad

"As for Ali, he never visited Fahad."

"ALI never visited Fahad."

*"Ali never visited Fahad."

We could see in (46), the subject $A l i$ is interpreted as a topic or a focus; the neutral interpretation of the subject renders the sentence ungrammatical.

In this subsection, I have shown that the ma-adverb like ma 9umr "never" appear only preverbally. And that the subject can appear to the left of this adverb for a topic or a focus interpretation; in this case, a clitic surfaces onto the adverb. In the next subsection, I will discuss the postverbal adverbs.

\subsubsection{Postverbal Adverbs}

This subsection concerns the postverbal adverbs like bjid "hard", bquuah "strongly" and bhiduu "calmly". In a neutral sentence, these adverbs can only appear clause final.

47. Ali dharabfahadbquuah

Ali hit Fahad strongly

"Ali hit Fahad strongly." 
48. *Ali (bquuah) dharab(bquuah)fahad

Ali stronglyhit strongly Fahad

"Ali hit Fahad strongly."

(47) shows that the adverb bquuah "strongly" appears clause final. Thus, the ungrammaticality of (48) is not surprising.

In a neutral sentence, the same adverb bquuah can appear in a position lower than the subject. In this case, it is interpreted as "with confidence" modifying the subject $\mathrm{Ali}$.

49. Ali bquuahdharabfahad

Ali with confidence hit Fahad

"Ali with confidence hit Fahad."

*"Ali strongly hit Fahad."

We could see from (49) that, in a neutral sentence, the adverb bquuah "strongly" occupies a position to the right of the subject. Again, this is only when the adverb is interpreted as "with confidence" modifying the subject Ali. Contra Fassi's \& Nuha's, as in English (Jackendoff, 1972), this shows that in the dialect under investigation, the interpretation of the adverb varies depending on its position in the sentence.

The same postverbal adverbs can also appear preverbally at the left periphery of the clause when they are interpreted as foci. However, these adverbs contrast with the preverbal adverbs like a Hyaanan "often" in that they never appear at the left periphery of the clause as topics. I will not say for sure why this is the case; but, I would say that it is just difficult to have an "adverb of manner" as a topic of conversation. In addition, with this focus interpretation, the adverb is ambiguous; it is either modifies the subject or the verb. See the following sentence where the adverb appears at the left periphery of the clause.

50. Bquuah, Ali dharabfahad

\section{STRONGLY/WITH CONFIDENCE Ali hitFahad}

"STRONGLY/WITH CONFIDENCE, Ali hit Fahad."

*“As for strongly, Ali hit Fahad."

In (50), we could see that adverb bquuah appears clause-initial and is only interpreted as a focus. In this case, there is a pause right after the adverb as the comma shows. In this sentence, as the English glossing shows, the adverb is ambiguous, it either modifies the action verb dharab "hit" or the subject of the sentence Ali.

Now, when the subject Ali precedes the focused adverb bquuah "strongly", the subject Ali is always interpreted as a topic. Again, the adverb is ambiguous; it could be interpreted as an adverb that modifies the action dharab "hit" or it could be interpreted as an adverb that modifies the topicalized subject Ali.

51. Ali, bquuah, dharabfahad

\section{Ali STRONGLY/WITH CONFIDENCE hit Fahad}

"As for Ali, STRONGLY/WITH CONFIDENCE, he hit Fahad."

*"STRONGLY/WITH CONFIDENCE, Alihit Fahad."

In (51), the subject Ali precedes the focused adverb bquuah; as we could see, there are two different interpretations for the adverb, one interpretation in which the adverb modifies subject and the other in which it modifies the action verb. As for the subject, it is only interpreted as a topic. Interestingly enough, the same adverb can appear in other positions inside the clause. In these positions, the adverb bquuah is interpreted as a focus modifying the subject Ali or the action verb yadhrib "hit". In any case, there is a pause after the focused adverb.

52. ali rah (bquuah), yidhribfahad

\section{ali will STRONGLY/WITH CONFIDENCE hit Fahad}

"STRONGLY/WITH CONFIDENCE, Ali will hit Fahad."

*Ali will hit Fahad Strongly."

In (52), we could see that inside the clause, the adverb bquuahis always interpreted as a focus modifying either the subject Ali or the action verb yadhrib "hit".

it seems that the postverbal adverbs like bquuah "strongly" are interpreted neutrally if and only if they come 
postverbally or right after the neutral subject; in other positions inside the clause, those adverbs are interpreted as foci; they receive high pitch and a pause is used. What is important is that ambiguity arises; they either modify the subject or the action verb. I will not say for sure why this is the case.

In this subsection, I have shown that the postverbal adverb like bquuah "strongly" appear clause final where they are interpreted as neutral. The same adverbs appear in a position right to the subject. In this case, the adverb modifies the subject rather than the verb. Contra Fassi's \& Nuha's, as in English (Jackendoff, 1972), this shows that in the dialect under investigation, the interpretation of the adverb varies depending on its position in the sentence. The same adverbs can appear in other positions, at the left periphery or inside the clause, as foci; in this case, the adverbs are ambiguous; that is to say, they modify either the main verb or the subject of the sentence. Next, sentential subjects are discussed.

\subsubsection{Sentential Adverbs}

In a neutral sentence, sentential adverbs always occur clause initially. They modify the entire clause and are distinguished from other adverbs in neutral sentences in that they are separated from the clause by a comma. (Cobb, 2006, who refers to them as disjunct adverbs).

53. wikaad, alizaarfahad

truly, Ali visited Fahad

"Truly, Ali visited Fahad."

54. * ali, (wikaad) zaar(wikaad) fahad (wikaad)

Ali truly, visited truly Fahad truly

"Truly, Ali visited Fahad."

In (53), we could see that the adverb wikaad "truly" appears in a sentence-initial position. As shown from (54), its appearance in other positions renders the sentence ungrammatical. However, those sentential adverbs could appear in the clause final position if and only if the entire sentence is focused or the subject is topicalized and the verb and its object are focused.

55. alizaarfahad, wikaad

Ali visited Fahad, wikaad

"Truly, ALI VISITED FAHAD."

*"Truly, Ali visited Fahad."

56. ali, zaarfahad, wikaad

Ali visited Fahad, wikaad

"Truly, as for Ali, he VISITED FAHAD."

*“Truly, Ali visited Fahad."

In (55), the adverb wikaad "truly" surfaces clause-final; in this sentence, the verb phrase and subject alizaarfahad "Ali visited Fahad"are focused. In (56), the subject Ali is topicalized and the verb and its object zaarfahad "visited Fahad" are focused; that is clear from the why those elements are uttered; they receive high pitch compared to the adverb wikaad "truly". Again, we notice the use of the comma indicating apause.

In this subjection, I have shown that in a neutral sentence, sentential adverbs like wikaad "truly" always appear in the left periphery of the clause; they can appear clause final if and only if the subject and the verb phrase are focused or the subject is topicalized and the verb and its object are focused.

To conclude this section, with a neutral interpretation, I have shown that there are two main types of adverbs; adverbs like a Hyaanan "often" and ma-?umr "never" that only appear preverbally and adverbs like bquuah "strongly" and sir9ah "quickly" that only appear clause final. With an un-neutral interpretation, adverbs like aHyaanan "sometimes" and b-sir9ah "quickly" can appear in the left periphery of the clause or inside the clause. As for sentential adverbs like wikaad "truly", they always appear at the left periphery of the clause; they can appear clause final if and only if the subject and the verb phrase are focused or the subject is topicalized and the verb and its object are focused.

Before concluding this paper, recall that I have aforementioned that there are other adverbs in SNRDA; those adverbs that are referred to as degree adverbs which modify adjectives and other adverbs like heel/balheel, marrah, jidan, and ktheer "very/extremely". Neutrally, those adverbs follow the adjective they modify. See the 
following sentence.

\section{7. alial-thakiheel akhuuy}

Ali the smart very my brother

"Ali the very smart is my brother."

In (57), the adverb heel "very" is modifying the adjective al-thaki "the smart". What is interesting about these adverbs is that the same adverbials can appear before the adjective; in this case, the adverbs is uttered with high pitch compared to the rest of elements in the sentence. In addition, the definite article al- "the" is cliticized onto the adverb leaving the adjective without a definite article.

\section{8. aliAL-HEEL thakiakhuui}

\section{Ali THE VERY smart my brother}

"Ali THE VERY smart is my brother."

In (58), compared to (57), the adverb heel "very" with the definite article clitic al- "the" precedes the adjective thaki "smart" and is uttered with high pitch.

This distribution of the degree adverbs along with other preverbal and post-verbal adverbs as well as sentential adverbs in SNRDA shows that the syntax of adverbs is far more complicated than it seems to be.

\section{Conclusion}

With my belief that there is not a comprehensive theory for adverbs, Iatridou (1990), Bobaljik \& Jonas (1996), in this paper, I have investigated the morph-syntax and distribution of adverbs in one of the Saudi dialect of Arabic, Saudi Northern Region Dialect of Arabic (SNRDA); a dialect that is spoken in the Northern Region of Saudi Arabia. I have shown that adverbs at least in SNRDA are not descriptively as simple as it is assumed for other dialects of Arabic studied by Nuha (2005) and in the Modern Standard Arabic (MSA) investigated by Fassi $(1997,1998)$. What is interesting is that intonation plays role in where the adverbs appear and how they are interpreted; in addition, with the change of the adverb position, there is a change in the meaning. Now, taking into account the role of intonation, the questions that need to be addressed are how those adverbs are structurally licensed in this dialect and why with intonation difference adverbs become ambiguous; these questions and other remaining puzzles are left for future work.

\section{References}

Al-Aqad, M. (2013). Syntactic analysis of Arabic adverb's between Arabic and English: X bar theory. $\begin{array}{lllll}\text { International Journal of Language and Linguistics, } & \text { 1(3), } & \text { 70-74. }\end{array}$ http://dx.doi.org/10.11648/j.ij11.20130103.11

Al-Shammiry, K. (2007). The clause structure of Turaif Arabic (unpublished doctoral dissertation). University of Kansas, USA.

Baltin, M. R. (1982). A Landing site theory of movement rule. Linguistic Inquiry, 13, 1-38.

Bhatia, A. (2006). Testing universality of Cinque's heirarchy with respect of and SOV language: Adverb placement in Hindi. Proceedings of workshops in general Linguistics. Madison, USA, University of Wisconsin.

Belletti, A. (1990). Generalized verb movement: Aspects of verb syntax. Torino: Rosenberg and Sellier.

Belletti, A. (1994). Verb position: Evidence from Italian. In Lightfoot \& Horstein (Eds.), Verb Movement. Cambridge: Cambridge University Press. http://dx.doi.org/10.1017/cbo9780511627705.003

Bobaljik, J. D., \& Diane, J.(1996). Subject positions and the roles of TP. Linguistic Inquiry, 27, 195-236.

Cinque, G. (1994). On the relative order of certain "lower" Adverbs in Italian and French. In A. FassiFehri (Ed.), LinguistiqueCompareeetLangues au Maroc. Rabat, University of Rabat.

Cinque, G. (1999). Adverbs and functional heads. Ancrosslinguisticperspective. New York: Oxford University Press.

Cinque, G. (2004). Issues in adverbial syntax. Lingua, 114, 683-716. http://dx.doi.org/10.1016/S0024-3841(03)00048-2

Costa, J. (2000). Adverbs as adjuncts to non-universal functional categories: evidence from Portuguese. In A. Alexiadou \& P. Svenonius (Eds.), Adverbs and adjunction (pp. 19-32). Linguistics in Potsdam 6. 
Costa, J. (2004). A multifactorial approach to adverb placement: Assumptions, facts, and problems. Lingua, 711-753. http://dx.doi.org/10.1016/S0024-3841(03)00049-4

Ernst, T. (1984). Towards an integrated theory of adverb position in English. Bloomington, Indiana: Indiana University Linguistics Club.

Ernst, T. (1998). The scopal basis of adverb licensing. In P. Tamanji \& K. Kusumoto (Eds.), The proceedings of the North East Linguistic Society (pp. 127-142). Amherst, Mass.

Ernst, T. (2002). The syntax of adverbial distribution in the lower clause. Lingua, 114, 755-778. http://dx.doi.org/10.1016/S0024-3841(03)00050-0

Emonds J. (1976). A transformational approach to English syntax, Root, Structure-Preserving and Local Transformation. New York: Academic Press.

Emonds, J. (1985). A unified theory of syntactic categories. Dordrecht: Foris. http://dx.doi.org/10.1515/9783110808513

FassiFehri, A. (1993). Issues in the structure of Arabic clauses and words. Dordrecht: Kluwer.

FassiFehri, A. (1997). Arabic adverbs and their case. Linguistic Research, 3, 1-25.

FassiFehri, A. (1998). Layers in the distribution of adverbs and adjectives and their licensing. In E. Benmamoun, E. Mushiraand, \& N. Hreri (Eds.), Perspectives on Arabic Linguistics 11. Amsterdam: John Benjamins Publishers.

FassiFehri, A. (2013). Arabic perfect and temporal adverbs. In A. Alexiadou, M. Rathert, \& A. von Stechow (Eds.), Perfect Explanations (pp. 69-99). Berlin: De Gruyter.

Haider, H. (2000). Adverb placement-convergence of structure and lincensing. Theoretical Linguistics, 26, 95-134. http://dx.doi.org/10.1515/thli.2000.26.1-2.95

Haider, H. (2004). Pre-postverbal adverbials in OV and VO. Lingua, 114, 779-807.

Iatridou, S. (1990). About Agr P. Linguistics Inquiry, 21, 551-557.

Jackendoff, R. (1972). Semantic interpretation in generative grammar. Cambridge: MIT Press.

Kayne, R. (1994). The antisymmetry of syntax. Cambridge, Mass: MIT Press.

Keyser, S. (1968). Review of Sven Jacobson, adverbial position in English. Language, 44, 357-374. http://dx.doi.org/10.2307/411633

Nuha, S. (2005). Word order, functions, and morphosyntactic features of adverbs and adverbials in Arabic. KSA, Journal of King Saud University, 18, 85-100.

Pollock, J. (1989). Verb movement, universal grammar, and the structure of IP. Linguistics Inquiry, 20, 365-424.

Pollock, J. (1997). Notes on clause structure. In L. Haegeman (Ed.), Elements of Grammar: handbook in Generative Syntax (pp. 237-279). Dordrecht: Klumer.

Potsdam, E. (1997). A syntax for adverbs (pp. 397-411). Ms. In the proceeding of the twenty-seventh conference on Linguistics, California, California State University. Retrieved from http://users.cls.ufl.edu/potsdam/papers/WECOL27.pdf

Rizzi, L. (1997). The fine structure of the left periphery". In L. Haegeman (Ed.), Elements of Grammar: handbook in Generative Syntax (pp. 281-337). Drodrecht: Klumer.

Stephen, W., \& Syse, P. (2001). Adverbs and functional heads in Turkish: Linear Order and Scope. Proceedings of Western Conference on Linguistics (WECOL). Retrieved from http://www.neuroling.arizona.edu/papers/wilsonsaygin03wecol.pdf

Travis, L. (1988) The Syntax of adverbs. Proceedings of the ninth workshop on comparative Germanic syntax (pp. 280-310).

\section{Notes}

Note 1. Shortly, it will be shown why I have labeled those type of adverbs as $b$-prefixed nouns.

Note 2. Nothing can come between the verb and its object. 


\section{Copyrights}

Copyright for this article is retained by the author(s), with first publication rights granted to the journal.

This is an open-access article distributed under the terms and conditions of the Creative Commons Attribution license (http://creativecommons.org/licenses/by/3.0/). 